\section{4-Butyl-1,2-diphenylpyrazolidine and Its Conformation Based on NMR Spectrometry}

\section{K. BERG-NIELSEN}

\section{Kjemisk Institutt, Universitetet $i$ Oslo, Oslo 3, Norway}

$\mathrm{T}_{\mathrm{h}}^{\mathrm{h}}$ he ring inversion of a five-membered ring is usually much faster than the pyramidal nitrogen inversion. ${ }^{1}$ In $1,2,4,4$ tetramethylpyrazolidine the inversion about the two nitrogen atoms has been studied by NMR spectroscopy. ${ }^{1}$ At low temperature the protons at 3 and 5 position appeared as two identical $\mathrm{AB}$ quartets. The coalescence temperature was found to be $-45^{\circ} \mathrm{C}$ in dichloromethane and the inversion barrier $\Delta G \neq=11.1 \mathrm{kcal} / \mathrm{mol}$.

Inversion of pyramidal nitrogen passes through a planar transition state. ${ }^{2}$ The conjugation of the lone pair with a phenyl substituent is expected to give the nitrogen sites a more planar shape and to decrease the inversion barrier. This decrease may be calculated by the empirical equation ${ }^{3}$

$$
\Delta G^{\ddagger}{ }_{1}=\mathrm{XZ}=\Delta G_{\mathrm{CH}_{3}} \mathrm{Z}_{1}
$$

where $Z_{1}$ represents the substituent and $X$ the rest of the molecule. Choosing methyl as unity $\left(Z_{\mathrm{CH}_{3}}=1\right)$ gives $\Delta G^{\neq}{ }_{\mathrm{CoH}_{s}}=$

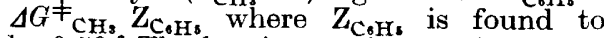
be $0.59 .^{6}$ The barrier to nitrogen inversion in 4,4-dimethyl-1,2-diphenylpyrazolidine may thus be calculated as $11.1 \times 0.59 \sim 6.55$ $\mathrm{kcal} / \mathrm{mol}$.

Pyrazolidine-3-ones can be reduced by lithium aluminjum hydride in a suitable solvent to the corresponding pyrazolidines. ${ }^{4-6}$

In continuation of our work with lithium aluminium hydride reduction of acyl hydrazobenzenes ${ }^{7}$ also 4-butyl-1,2-diphenylpyrazolidine-3,5-dione has now been

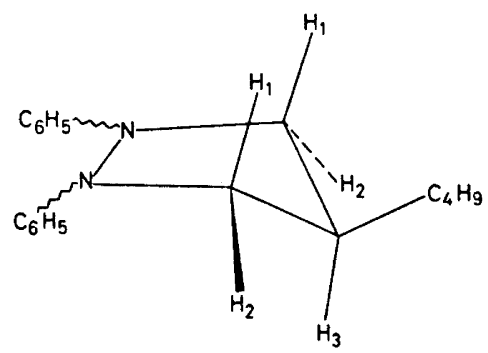

(I) reduced to 4-butyl-1,2-diphenylpyrazolidine (I).

The NMR shifts for $H_{1}$ and $H_{2}$ are temperature dependent. The difference between them, $\Delta v$, in Freon 21 is $0.93 \mathrm{ppm}$ at $-90^{\circ} \mathrm{C}$ and $0.84 \mathrm{ppm}$ at $0^{\circ} \mathrm{C}$. In carbon tetrachloride $\Delta v$ is $0.80 \mathrm{ppm}$ at $0^{\circ} \mathrm{C}, 0.77$ $\mathrm{ppm}$ at $29^{\circ} \mathrm{C}$, and $0.72 \mathrm{ppm}$ at $73^{\circ} \mathrm{C}$, the coupling picture being the same.

Thus the nitrogen inversion is, as expected, too fast to give a low-temperature spectrum at $-90^{\circ} \mathrm{C}$, which should correspond to a barrier lower than $c a .8 .5$ $\mathrm{kcal} / \mathrm{mol}$.

Since corresponding protons at $\mathrm{C}_{3}$ and $\mathrm{C}_{5}$ are identical at all temperatures, the rapid inversion must produce a plane of symmetry in the molecule perpendicular to and through the middle of the $\mathrm{N}-\mathrm{N}$ bond.

The difference in chemical shifts for $\mathrm{H}_{1}$ and $\mathrm{H}_{2}, 0.77 \mathrm{ppm}$, is too large to be caused by the butyl group only; it must be due to shielding and deshielding effects of the benzene rings. The NMR spectra therefore indicate that the energy minimum of the ring corresponds to $C_{s}$ symmetry with the butyl group in "equatorial" position at the tip of the envelope.

Because of the butyl group all other conformations have higher energy. Their population must increase somewhat with temperature to explain the decrease in $\Delta v$ between $H_{1}$ and $H_{2}$. Possibly some kind of solvent interaction is also involved.

1,2-Diphenylpyrazolidine has no substituents at $\mathrm{C}_{4}$ providing energy difference of this kind. In its NMR spectrum the $\mathrm{H}_{1}$ and $\mathrm{H}_{2}$ protons therefore appear as a triplet at $\delta 3.43, J=6.5 \mathrm{~Hz}$ showing that they are equal. The protons at $\mathrm{C}_{4}$ appear as a quintet at $\delta 1.94$.

Models of 4-butyl-1,2-diphenylpyrazolidine (II and III) suggest a difference in shielding and deshielding effects at $H_{1}$ and $\mathrm{H}_{2}$ in good agreement with the found values (Fig. 1). When the adjacent phenyl group is trans to $\mathrm{H}_{2}$ (II), this proton will be very near to the plane of the benzene ring and therefore in the deshielding zone. At the same time $H_{1}$ will be in the shielding zone. The other phenyl group is more remote and gives a smaller effect, only a slight shielding effect at $\mathrm{H}_{2}$. When the adjacent phenyl group is trans to $\mathrm{H}_{1}$, (III), the distance from the ring to $H_{1}$ is greater and the deshielding effect will be reduced. $\mathrm{H}_{2}$ in (III) will be less shielded than $\mathrm{H}_{1}$ in (II). The other phenyl group gives only a slight shielding effect at $\mathrm{H}_{1}$.

An inspection of a model of this molecule 
Table 1. The NMR spectrum of (I) in carbon tetrachloride at $29^{\circ} \mathrm{C}$ in $\delta$ values.

\begin{tabular}{|c|c|c|c|c|c|c|c|c|}
\hline $\mathrm{C}_{6} \mathrm{H}_{5}$ & & $\mathrm{H}$ & & $\mathrm{H}_{2}$ & & $\mathrm{H}_{3}$ & & $\mathrm{C}_{4} \mathrm{H}_{9}$ \\
\hline $8.25-6.64$ & $10 \mathrm{H}$ & $2.93 t$ & $2 \mathrm{H}$ & $3.70 \mathrm{~d}$ & $2 \mathrm{H}$ & $\sim 2.3 \mathrm{c}$ & $1 \mathrm{H}$ & $\begin{array}{ll}0.86 \mathrm{t} & 3 \mathrm{H} \\
1.31 \mathrm{c} & 6 \mathrm{H}\end{array}$ \\
\hline
\end{tabular}

$\mathrm{t}=$ triplet, $\mathrm{d}=2$ doublets, $\mathrm{c}=$ complex; $J_{1,2}=9.8 \mathrm{~Hz}, J_{1,3} \approx 9.4 \mathrm{~Hz}, J_{2,3}=7.0 \mathrm{~Hz}$.

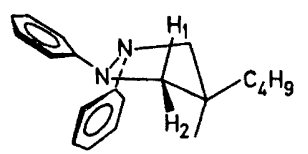

(II)

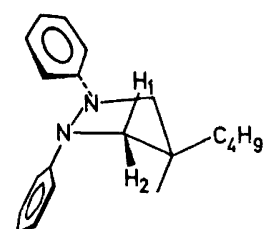

(III)

$\underbrace{\begin{array}{l}H_{1} \text { shielded } \\ H_{2} \text { deshielded }\end{array} H_{2}^{H_{1} \text { slightly deshielded }}}_{\begin{array}{l}H_{1} \text { shielded } \\ H_{2} \text { deshielded }\end{array}}$

Fig. 1. Models of 4-butyl-1,2-diphenylpyrazolidine showing shielding and deshielding effects of the benzene rings at $\mathrm{H}_{1}$ and $\mathrm{H}_{2}$.

also shows that the dihedral angle between $H_{1}$ and $H_{3}, \theta_{1,3}$, is closer to $180^{\circ}$ than the dihedral angle between $\mathrm{H}_{2}$ and $\mathrm{H}_{3}, \theta_{2,3}$, is close to zero. The observed coupling constants $J_{1,3}=9.4 \mathrm{~Hz}>J_{2,3}=7.0 \mathrm{~Hz}$ are therefore in agreement with values predicted from the Karplus equation.

Experimental. Melting points were determined on a micro hot-stage. NMR spectra were recorded on Varian A-60 A and HA 100 Spectrometers with tetramethylsilane as internal reference, mass spectra on an AEI/EC MS 902 instrument, and infrared spectra on a Perkin-Elmer 457 Grating Infrared Spectrophotometer. Thin layer chromatography was used with toluene as eluent and iodine vapour as staining reagent.

4-Butyl-1,2-diphenylpyrazolidine (I). To a solution of 4-butyl-1,2-diphenylpyrazolidine3,5-dione $(6.2 \mathrm{~g}, 20 \mathrm{mmol})$ in dry ether $(40 \mathrm{ml})$ was added a suspension of lithium aluminium hydride $(2.7 \mathrm{~g}, 70 \mathrm{mmol})$ in dry ether $(40 \mathrm{ml})$, and the mixture was refluxed for $2 \mathrm{~h}$. After cooling, water $(5 \mathrm{ml})$ was added cautiously and then $2 \mathrm{~N}$ sodium hydroxide $(2 \mathrm{ml})$. After 30 min the solid material was filtered off and the solution dried with calcium chloride. The ether was removed at low pressure and the product purified by column chromatography on alumi- nium oxide with toluene as eluent. The yield was $1.8 \mathrm{~g}(31 \%)$ of a liquid which was not further purified. It was kept at $-10^{\circ} \mathrm{C}$ to avoid darkening. The IR spectra showed no absorption due to carbonyl. The mass spectrum. showed $m / e=280$.

1,2-Diphenylpyrazolidine. A dispersion of hydrazobenzene $(6.3 \mathrm{~g}, 33 \mathrm{mmol}), 1,3$-diiodopropane $(9.7 \mathrm{~g}, 33 \mathrm{mmol})$, and sodium hydrogen carbonate $(5.7 \mathrm{~g}, 66 \mathrm{mmol})$ in ethanol $(200 \mathrm{ml})$ was refluxed with stirring under nitrogen for $22 \mathrm{~h}$. Undissolved sodium iodide $(2.4 \mathrm{~g})$ was filtered off and the solvent removed at low pressure, leaving a solid residue $(13 \mathrm{~g})$. This was extracted with toluene $(3 \times 15 \mathrm{ml})$ giving more undissolved sodium iodide $(3.2 \mathrm{~g})$. The toluene was evaporated in vacuo, and the solid residue was extracted thoroughly with petrol ether, b.p. $60-80^{\circ} \mathrm{C}(4 \times 15 \mathrm{ml})$, leaving hydrazobenzene undissolved $(4.8 \mathrm{~g})$. The petrol ether was removed at low pressure, and the residue solidified on cooling. It was then washed with some petrol ether $(3 \times 4 \mathrm{ml})$ leaving $0.9 \mathrm{~g}$ $(13 \%)$ of a white product, m.p. $99.5-100.5^{\circ} \mathrm{C}$ after crystallization from ethanol. (Lit. 96$98^{\circ} \mathrm{C}^{9}$ and $98.5-99^{\circ} \mathrm{C}^{10}$.) The mass spectrum showed $m / e=224$.

1. Lehn, J. M. Fortschr. Chem. Forsch. 15 (1970) 311 .

2. Kessler, H. Angew. Chem. 82 (1970) 244.

3. Kessler, H. and Leibfritz, D. Tetrahedron Letters 19704297.

4. Bouchet, P., Elguero, J. and Jacquier, R. Tetrahedron 22 (1966) 2461.

5. Dittli, C., Elguero, J. and Jacquier, R. Bull. Soc. Chim. France 19694469.

6. Elguero, J., Jacquier, R. and Tizané, D. Bull. Soc. Chim. France 19701936.

7. Berg-Nielsen, K. and Bernatek, E. Acta Chem. Scand. 26 (1972) 4130.

8. Eliel, E. L., Allinger, N. L., Angyal, S. J. and Morrison, G. A. Conformational Analysis, Interscience, New York 1966, p. 60.

9. Wittig, G., Joos, W. and Rathfelder, P. Ann. 610 (1957) 180.

10. Daniels, R. and Martin, B. D. J. Org. Chem. 27 (1962) 178.

Received February 6, 1973. 